\title{
KESESUAIAN Komponen KaWASAN Wisata KaMPUng LaWEYaN Terhadap ASPEK ReVitalisasi KaWASAN Wisata Cagar Budaya
}

\author{
BAYU SETO AJI PRAMANA ${ }^{1}$ \\ PROGRAM STUDI PERENCANAAN WILAYAH DAN KoTA \\ FAKULTAS TEKNIK \\ UNIVERSITAS SEBELAS MARET, SURAKARTA \\ email: bayuzeto13@gmail.com \\ KUSUMASTUTI \\ Program Studi PERENCANAAN WilayaH DAN Kota \\ FAKULTAS TEKNIK \\ PUSAT INFORMASI DAN PEMBANGUNAN WILAYAH (PIPW), LPPM \\ UNIVERSITAS SEBELAS MARET, SURAKARTA \\ RUFIA ANDISETYANA PUTRI ${ }^{3}$ \\ PROGRAM STUDI PERENCANAAN WILAYAH DAN KOTA \\ FAKULTAS TEKNIK \\ PUSAT INFORMASI DAN PEMBANGUNAN WILAYAH (PIPW), LPPM \\ UNIVERSITAS SEBELAS MARET, SURAKARTA
}

\begin{abstract}
Solo city which is formed from a long history has a distinctive character that is on aspects of culture and history. History and culture can not be separated from the development of the city because the city is also formed from past activities that become historical value in the present. One area in the city of Solo which has a strong historical and cultural character is "Kampung Laweyan". It makes "Kampung Laweyan" become one of the unique areas and has potential that can be developed, the potential and unique characteristics of Kampung Laweyan is as a tourist attraction that presents cultural attractions and traditions that are still thick, especially the culture and tradition of batik. But the development of science and technology, making the historical and cultural aspects of urban development is increasingly lagging behind. The existence of "Kampung Laweyan" which put forward the historical and cultural aspects in its development also increasingly degenerate, so that the vitality of this region is also declining. Therefore in 2004 the revitalization began to revitalize the area into a tourist destination. This revitalization also reviewed its suitability as the Heritage Tourism Area. This research aims to determine the level of suitability Aspects of revitalization Tourism Laweyan Heritage Area. The method used in this research is deductive through scoring technique analysis. The data used are primary data through field observation and interview and secondary data through document study. The result of the research shows that only the aspect of the activity actor has the corresponding value while the other two aspects of tourist attraction and physical facility have unsuitable value. So that the overall assessment of conformity Aspect Revitalization of Heritage Tourism Area also has unsuitable value.
\end{abstract}

Keywords: Heritage Tourism Area, Revitalization 


\section{PENDAHULUAN}

Pada masa sekarang dalam perkembangannya suatu wilayah maupun perkotaan lebih mengedepankan aspek-aspek modern (IPTEK) dalam pengembangannya, sehingga bangunan maupun kawasan di perkotaan yang mengandung nilai sejarah dan budaya terekspansi akan perkembangan tersebut. Bangunan maupun kawasan cagar budaya itupun terus tergerus eksistensinya dalam perkembangan suatu kota atau wilayah. Bahkan beberapa bangunan tua dibiarkan begitu saja tanpa ada perlindungan dan perawatan.

Kampung Batik Laweyan sebagai salah satu kawasan cagar budaya yang ada di Kota Surakarta yang memiliki banyak nilai budaya dan sejarah menyimpan potensi yang dapat di kembangkan, yaitu menjadi salah satu kawasan wisata cagar budaya yang ada di Kota Surakarta ini. Polemik terbesar yang terjadi di Kampung Batik Laweyan ini berawal dari munculnya teknik pembuatan batik printing yang lebih praktis serta terjadinya guncangan krisis ekonomi pada tahun 1997 yang membuat eksistensi kampong laweyan ini terus merosot karena tidak bisa mengikuti perkembangan zaman. Majah [2015] mengatakan bahwa pasca krisis ekonomi 1997 kondisi Laweyan berangsur membaik dengan tumbuhnya jenis-jenis usaha baru di Laweyan. Masyarakat Laweyan pun sudah mulai terbuka terhadap masyarakat luar, di samping itu Laweyan juga mulai kembali melestarikan berbagai tradisi kebudayaan setelah sebelumnya hampir hilang".

Pada tanggal 24 Oktober 2004 Laweyan secara resmi di deklarasikan menjadi Kampung Wisata serta memiliki forum atau komunitas resmi dalam pengembangan perngelolaan Kampung
Laweyan tersebut yakni Forum Pengembangan Kampoeng Batik Laweyan (FPKBL)".

Dalam pengembangannya, pada kawasan ini telah dilakukan revitalisasi guna memvitalkan kembali serta mempertahankan eksistensi aspekaspek sejarah dan budaya yang menjadi fokus utama pengembangan pada kawasan tersebut. Danisworo [2002] mengatakan bahwa aspek-aspek yang dapat dilihat pada proses revitalisasi ini mencakup aspek fisik, aspek ekonomi dan aspek sosial, serta harus mampu mengenali dan memanfaatkan potensi lingkungan (sejarah, makna, keunikan lokasi dan citra tempat).

Tabel 1 Jumlah Pengunjung Penginapan

\begin{tabular}{|c|c|c|}
\hline $\mathbf{2 0 1 3}$ & $\mathbf{2 0 1 4}$ & $\mathbf{2 0 1 5}$ \\
\hline 575 & 550 & 513 \\
\hline \multicolumn{3}{|c|}{ Sumber: Kecamatan Laweyan dalam Angka 2016}
\end{tabular}

Dengan melihat semakin menurunnya jumlah pengunjung yang ada maka, revitalisasi ini bertujuan bukan hanya menjaga estetika dan nilai sejarah yang terkandung dalam kawasan dan bangunan cagar budaya, namun juga memperhatikan sustainable dengan memperhatikan nilai ekonomi dan budaya. Sehingga potensi-potensi dalam kawasan terutama potensi sejarah dan budaya pun terus bisa dikembangkan sesuai dengan arus globalisasi yang ada. Kemudian Kawasan Kampung Batik Laweyan ini pun menjadi Kawasan Wisata Berkelanjutan unggulan di Kota Surakarta. Penelitian ini dilakukan dengan mengidentifikasi komponen kawasan wisata kampung batik laweyan yang kemudian mengidentifikasikannya terhadap aspek revitalisasi kawasan wisata cagar budaya, sehingga tingkat kesesuaian terhadap aspek revitalisasi Kawasan Wisata Cagar Budaya Laweyan ini bisa diketahui. 


\section{TINJAUAN PUSTAKA}

[Danisworo, 2002] "aspek-aspek yang dapat dilihat pada proses revitalisasi ini mencakup aspek fisik, aspek ekonomi dan aspek sosial, serta harus mampu mengenali dan memanfaatkan potensi lingkungan (sejarah, makna, keunikan lokasi dan citra tempat)". Aspek fisik/ lingkungan yang dimaksud adalah 8 elemen citra lingkungan yaitu tata guna tanah, bentuk dan masa bangunan, sirkulasi dan parkir, ruang terbuka, jalur pejalan kaki, activity support, simbol dan tanda serta preservation [Shirvani, 1985, dalam Mulyandari 2010].

Komponen-komponen kawasan wisata menurut [Yoeti,1982] "komponenkomponen kawasan wisata yang harus ada dalam suatu kawasan wisata yaitu Daya Tarik Wisata (Site attraction dan event attraction), Pelaku Kegiatan dan Fasilitas Wisata". Menurut [Inskeep, 1991] "ada beberapa komponen wisata yang merupakan dasar dari kawasan wisata. Komponen-komponen ini saling terintegrasikan satu sama lain dalam mewujudkan kegiatan kawasan wisata, komponen tersebut yaitu atraksi wisata dan kegiatan wisata, fasilitas dan pelayanan akomodasi, fasilitas dan pelayanan wisata lain, fasilitas dan pelayanan trasportasi, infrastruktur dan aspek kelembagaan".
Aspek/ komponen yang menjadi fokus penelitian ini adalah hasil dari persilangan aspek revitalisasi dengan aspek kawasan wisata cagar budaya yaitu terjaganya kelestarian bangunan cagar budaya sebagai daya tarik, budaya dan tradisi sebagai daya tarik, produktifitas ekonomi lokal pada sektor pariwisata, kelembagaan dan ketersediaan infrastruktur fisik wisata. Aspek- aspek tersebut yang nantinya menjadi variabel-variabel yang dinilai pada penelitian ini.

\section{METODE PENELITIAN}

Metode penelitian ini berisi ruang lingkup penelitian dan metode analisis yang digunakan untuk mengetahui tingkat kesesuaian komponen revitalisasi kawasan wisata cagar budaya Laweyan

\subsection{Ruang Lingkup}

Ruang lingkup wilayah penelitian ini adalah seluruh wilayah Kampung Batik Laweyan beserta Kawasan Cagar Budaya yang masih menjadi bagian kawasan. Jadi bukan hanya terpaku pada sentra batiknya saja namun juga pada benda atau bangunan-bangunan cagar budaya yang terkait. Laweyan menjadi kawasan studi penelitian dikarenakan pada kawasan laweyan ini sudah menjadi salah satu prioritas akan konservasi kawasan yang ada di Kota Surakarta karena telah menjadi Kawasan Strategis Cagar Budaya. 


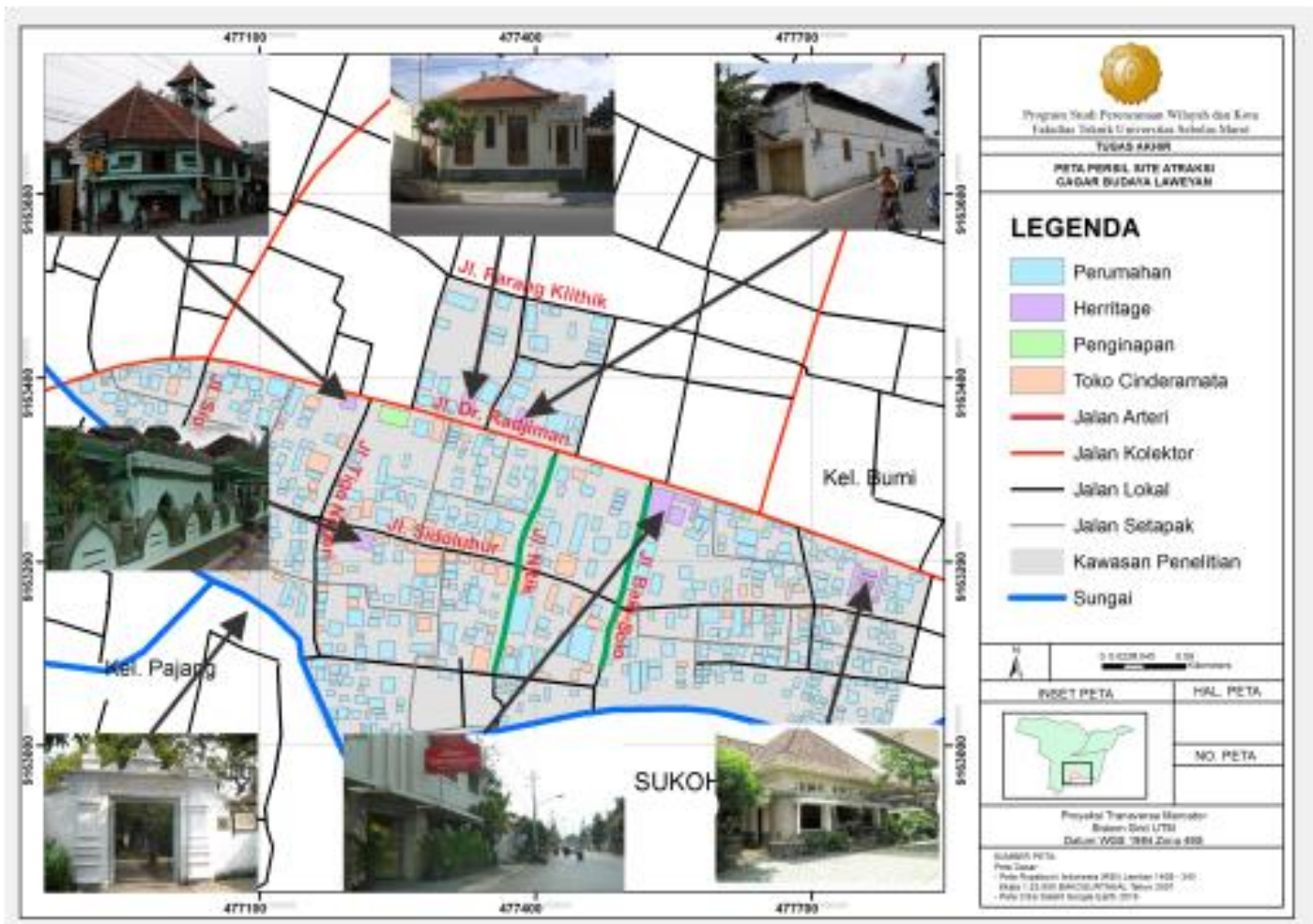

Gambar 1. Peta Wilayah Penelitian

\subsection{Metode Analisis}

Pada penelitian ini dilakukan teknik analisis dengan melalui pendekatan Scoring. Dalam analisis ini penjelasan antar variabelnya akan dibahas lebih terperinci secara deskriptif kualitatif. Teknik analisis yang akan dipakai dalam mengukur tingkat kesesuaiannya menggunakan teknik analisis skoring, dimana masing-masing variabel akan diberikan bobot yang sama. Berikut adalah peniliaan masing-masing variabel berdasarkan penilaian tiap sub variabelnya.

Tabel 2. Variabel Penelitian dan indikator penelitian

\begin{tabular}{|c|c|c|c|c|c|c|}
\hline \multirow[t]{2}{*}{ No } & \multirow[t]{2}{*}{ Variabel } & \multirow{2}{*}{$\begin{array}{c}\text { Sub } \\
\text { Variabel }\end{array}$} & \multirow[t]{2}{*}{ Parameter } & \multicolumn{3}{|c|}{ Indikator } \\
\hline & & & & 3 & 2 & 1 \\
\hline \multirow{3}{*}{1} & \multirow{3}{*}{$\begin{array}{l}\text { Daya } \\
\text { Tarik } \\
\text { Wisata }\end{array}$} & \multirow[t]{3}{*}{$\begin{array}{l}\text { Terjaganya } \\
\text { Kelestarian } \\
\text { Bangunan } \\
\text { Cagar } \\
\text { Budaya } \\
\text { sebagai } \\
\text { Daya Tarik }\end{array}$} & $\begin{array}{l}\text { Terlindungann } \\
\text { ya Bangunan } \\
\text { Cagar Budaya }\end{array}$ & $\begin{array}{l}\text { Jika } \\
\text { keseluruhan } \\
\text { bangunan cagar } \\
\text { budaya yang } \\
\text { ada telah } \\
\text { terlindungi }\end{array}$ & $\begin{array}{l}\text { Jika } 50-99 \% \text { dari } \\
\text { jumlah } \\
\text { keseluruhan } \\
\text { bangunan cagar } \\
\text { budaya yang ada } \\
\text { telah terlindungi }\end{array}$ & $\begin{array}{l}\text { Jika }<50 \% \text { dari } \\
\text { jumlah } \\
\text { keseluruhan } \\
\text { bangunan cagar } \\
\text { budaya yang ada } \\
\text { telah terlindungi }\end{array}$ \\
\hline & & & $\begin{array}{l}\text { Perawatan } \\
\text { Bangunan } \\
\text { Cagar Budaya }\end{array}$ & $\begin{array}{l}\text { Jika } \\
\text { keseluruhan } \\
\text { bangunan cagar } \\
\text { budaya yang } \\
\text { ada telah } \\
\text { dirawat }\end{array}$ & $\begin{array}{l}\text { Jika } 50-99 \% \text { dari } \\
\text { jumlah } \\
\text { keseluruhan } \\
\text { bangunan cagar } \\
\text { budaya yang ada } \\
\text { telah dirawat }\end{array}$ & $\begin{array}{l}\text { Jika }<50 \% \text { dari } \\
\text { jumlah } \\
\text { keseluruhan } \\
\text { bangunan cagar } \\
\text { budaya yang ada } \\
\text { telah dirawat }\end{array}$ \\
\hline & & & $\begin{array}{l}\text { Bangunan } \\
\text { Cagar Budaya } \\
\text { sebagai } \\
\text { atraksi wisata }\end{array}$ & $\begin{array}{l}\text { Jika } \\
\text { keseluruhan } \\
\text { bangunan cagar } \\
\text { budaya yang } \\
\text { ada } \\
\text { dimanfaatkan } \\
\text { sebagai obyek } \\
\text { wisata }\end{array}$ & $\begin{array}{l}\text { Jika } 50-99 \% \text { dari } \\
\text { jumlah } \\
\text { keseluruhan } \\
\text { bangunan cagar } \\
\text { budaya yang ada } \\
\text { dimanfaatkan } \\
\text { sebagai obyek } \\
\text { wisata }\end{array}$ & $\begin{array}{l}\text { Jika }<50 \% \text { dari } \\
\text { jumlah } \\
\text { keseluruhan } \\
\text { bangunan cagar } \\
\text { budaya yang ada } \\
\text { dimanfaatkan } \\
\text { sebagai obyek } \\
\text { wisata }\end{array}$ \\
\hline
\end{tabular}


Bayu Seto Aji Pramana dkk, Kesesuaian Komponen Revitalisasi...

\begin{tabular}{|c|c|c|c|c|c|c|}
\hline \multirow[t]{4}{*}{ No } & \multirow[t]{4}{*}{ Variabel } & \multirow{2}{*}{$\begin{array}{c}\text { Sub } \\
\text { Variabel }\end{array}$} & \multirow[t]{2}{*}{ Parameter } & \multicolumn{3}{|c|}{ Indikator } \\
\hline & & & & 3 & 2 & 1 \\
\hline & & \multirow[t]{2}{*}{$\begin{array}{l}\text { Budaya } \\
\text { dan Adat } \\
\text { Tradisi } \\
\text { sebagai } \\
\text { Daya Tarik }\end{array}$} & $\begin{array}{l}\text { Pelestarian } \\
\text { Budaya dan } \\
\text { Tradisi }\end{array}$ & $\begin{array}{l}100 \% \text { dari } \\
\text { keseluruhan } \\
\text { penyelenggaraa } \\
\text { n kegiatan } \\
\text { budaya dan } \\
\text { tradisi } \\
\text { dilakukan } \\
\text { secara terjadwal } \\
\text { dan kontinu }\end{array}$ & $\begin{array}{l}\text { 50-99\% dari } \\
\text { keseluruhan } \\
\text { penyelenggaraa } \\
\text { n kegiatan } \\
\text { budaya dan } \\
\text { tradisi dilakukan } \\
\text { secara terjadwal } \\
\text { dan kontinu }\end{array}$ & $\begin{array}{l}<50 \% \text { dari } \\
\text { keseluruhan } \\
\text { penyelenggaraan } \\
\text { kegiatan budaya } \\
\text { dan tradisi } \\
\text { dilakukan secara } \\
\text { terjadwal dan } \\
\text { kontinu }\end{array}$ \\
\hline & & & $\begin{array}{l}\text { Budaya dan } \\
\text { tradisi } \\
\text { sebagai } \\
\text { atraksi wisata }\end{array}$ & $\begin{array}{l}100 \% \text { dari } \\
\text { keseluruhan } \\
\text { kegiatan } \\
\text { budaya dan } \\
\text { tradisi yang } \\
\text { dilakukan } \\
\text { menjadi atraksi } \\
\text { wisata }\end{array}$ & $\begin{array}{l}\text { 50-99\% dari } \\
\text { keseluruhan } \\
\text { kegiatan budaya } \\
\text { dan tradisi yang } \\
\text { dilakukan } \\
\text { menjadi atraksi } \\
\text { wisata }\end{array}$ & $\begin{array}{l}<50 \% \text { dari } \\
\text { keseluruhan } \\
\text { kegiatan budaya } \\
\text { dan tradisi yang } \\
\text { dilakukan } \\
\text { menjadi atraksi } \\
\text { wisata }\end{array}$ \\
\hline \multirow[t]{5}{*}{2} & \multirow{5}{*}{$\begin{array}{l}\text { Pelaku } \\
\text { Kegiatan }\end{array}$} & \multirow{3}{*}{$\begin{array}{l}\text { Kelembaga } \\
\text { an }\end{array}$} & $\begin{array}{l}\text { Perencana/ } \\
\text { penggerak } \\
\text { kawasan } \\
\text { wisata }\end{array}$ & $\begin{array}{l}\text { Jika terdapat } \\
\text { produk } \\
\text { perencanaan } \\
\text { yang memuat } 3 \\
\text { hal pokok } \\
\text { perencanaan } \\
\text { pariwisata (visi- } \\
\text { misi strategis } \\
\text { pariwisata, } \\
\text { tujuan-sasaran } \\
\text { dan strategi } \\
\text { pariwisata, serta } \\
\text { program dan } \\
\text { rencana } \\
\text { implementasi) }\end{array}$ & $\begin{array}{l}\text { Jika terdapat } \\
\text { produk } \\
\text { perencanaan } \\
\text { yang memuat } 1 \\
\text { atau } 2 \text { hal pokok } \\
\text { dalam } \\
\text { perencanaan } \\
\text { pariwisata }\end{array}$ & $\begin{array}{l}\text { Jika tidak } \\
\text { terdapat produk } \\
\text { perencanaan } \\
\text { pariwisata }\end{array}$ \\
\hline & & & $\begin{array}{l}\text { Media } \\
\text { promosi } \\
\text { kawasan } \\
\text { wisata }\end{array}$ & $\begin{array}{l}\text { Promosi } \\
\text { dilakukan } \\
\text { melalui } \\
\text { berbagai media } \\
\text { yang ada } \\
\text { (Cetak,Online,P } \\
\text { apan informasi, } \\
\text { Pusat Informasi } \\
\text { Wisata }\end{array}$ & $\begin{array}{l}\text { Promosi hanya } \\
\text { dilakukan pada } \\
\text { sebagian media }\end{array}$ & $\begin{array}{l}\text { Promosi } \\
\text { dilakukan hanya } \\
\text { melalui satu } \\
\text { media }\end{array}$ \\
\hline & & & $\begin{array}{l}\text { Monitoring } \\
\text { kawasan } \\
\text { wisata }\end{array}$ & $\begin{array}{l}\text { Dilakukan } \\
\text { upaya } \\
\text { pengendalian } \\
\text { berupa } \\
\text { pengawasan, } \\
\text { evaluasi, dan } \\
\text { perbaikan oleh } \\
\text { stakeholder } \\
\text { terkait }\end{array}$ & $\begin{array}{l}\text { Dilakukan upaya } \\
\text { pengendalian } \\
\text { berupa salah } \\
\text { satu atau dua } \\
\text { dari bentuk } \\
\text { pengendalian }\end{array}$ & $\begin{array}{l}\text { Tidak dilakukan } \\
\text { upaya } \\
\text { pengendalian } \\
\text { kegiatan } \\
\text { pariwisata }\end{array}$ \\
\hline & & $\begin{array}{l}\text { Kepuasaan } \\
\text { Pengunjun } \\
\mathrm{g}\end{array}$ & $\begin{array}{l}\text { Kepuasaan } \\
\text { Pengunjung }\end{array}$ & $\begin{array}{l}\text { Nilai kepuasaan } \\
\text { antara } \\
1766-2268\end{array}$ & $\begin{array}{l}\text { Nilai kepuasaan } \\
\text { antara } \\
1261-1765\end{array}$ & $\begin{array}{l}\text { Nilai kepuasaan } \\
\text { antara } \\
756-1260\end{array}$ \\
\hline & & $\begin{array}{l}\text { Produktivit } \\
\text { as } \\
\text { Ekonomi } \\
\text { Lokal }\end{array}$ & $\begin{array}{l}\text { Daya saing } \\
\text { tenaga kerja } \\
\text { sektor } \\
\text { pariwisata }\end{array}$ & $\begin{array}{l}\text { Jika hasil } \\
\text { analisis } \\
\mathrm{LQ}>1\end{array}$ & $\begin{array}{l}\text { Jika hasil analisis } \\
\mathrm{LQ}=1\end{array}$ & $\begin{array}{l}\text { Jika hasil analisis } \\
\mathrm{LQ}<1\end{array}$ \\
\hline 3 & $\begin{array}{l}\text { Fasilitas } \\
\text { Fisik } \\
\text { Wisata } \\
\end{array}$ & $\begin{array}{l}\text { Ketersedia } \\
\text { an } \\
\text { Infrastrukt } \\
\text { ur Fisik }\end{array}$ & $\begin{array}{l}\text { Ketersedian } \\
\text { Toko } \\
\text { Cinderamata }\end{array}$ & $\begin{array}{l}\text { Memberikan } \\
\text { penyediaan } \\
\text { toko } \\
\text { cinderamata }\end{array}$ & $\begin{array}{l}\text { Hanya } \\
\text { memenuhi salah } \\
\text { satu indikator }\end{array}$ & $\begin{array}{l}\text { Tidak memenuhi } \\
\text { semua indikator }\end{array}$ \\
\hline
\end{tabular}




\begin{tabular}{|c|c|c|c|c|c|c|}
\hline \multirow[t]{2}{*}{ No } & \multirow[t]{2}{*}{ Variabel } & \multirow{2}{*}{$\begin{array}{c}\text { Sub } \\
\text { Variabel }\end{array}$} & \multirow[t]{2}{*}{ Parameter } & \multicolumn{3}{|c|}{ Indikator } \\
\hline & & & & 3 & 2 & 1 \\
\hline & & $\begin{array}{l}\text { Kawasan } \\
\text { Wisata }\end{array}$ & & $\begin{array}{l}\text { - Masyarakat } \\
\text { menjadi } \\
\text { pelaku } \\
\text { kegiatan } \\
\end{array}$ & & \\
\hline & & & $\begin{array}{l}\text { Ketersediaan } \\
\text { Ruang } \\
\text { Terbuka Hijau }\end{array}$ & $\begin{array}{l}\text { - Tersedianya } \\
\text { Ruang } \\
\text { Terbuka } \\
\text { Hijau Aktif } \\
\text { - Tersedianya } \\
\text { Ruang } \\
\text { Terbuka } \\
\text { Hijau Pasif } \\
\end{array}$ & $\begin{array}{l}\text { Hanya } \\
\text { memenuhi salah } \\
\text { satu ruang } \\
\text { terbuka hijau } \\
\text { (Pasif atau Aktif) }\end{array}$ & $\begin{array}{l}\text { Tidak tersedianya } \\
\text { Ruang Terbuka } \\
\text { Hijau }\end{array}$ \\
\hline & & & $\begin{array}{l}\text { Ketersediaan } \\
\text { Jalur Pejalan } \\
\text { Kaki }\end{array}$ & $\begin{array}{l}\text { Memenuhi } \\
\text { semua indikator } \\
\text { yang ada } \\
\text { (Aman,Mudah } \\
\text { dan Nyaman) }\end{array}$ & $\begin{array}{l}\text { Hanya } \\
\text { memenuhi } \\
\text { sebagian } \\
\text { indikator }\end{array}$ & $\begin{array}{l}\text { Tidak memenuhi } \\
\text { indicator }\end{array}$ \\
\hline & & & $\begin{array}{l}\text { Ketersediaan } \\
\text { Akomodasi } \\
\text { Wisata }\end{array}$ & $\begin{array}{l}\text { - Sarana } \\
\text { Penginapan } \\
\text { melingkupi } \\
\text { kebutuhan } \\
\text { penginapan } \\
\text { dilihat dari } \\
\text { jangkauan } \\
\text { pelayanan } \\
\text { 400m } \\
\text { - Ketersediaa } \\
\text { n paket- } \\
\text { paket wisata } \\
\text { yang } \\
\text { memudahka } \\
\text { n wisatawan } \\
\text { dalam } \\
\text { mengkases } \\
\text { atraksi } \\
\text { wisata } \\
\end{array}$ & $\begin{array}{l}\text { Hanya } \\
\text { memenuhi } \\
\text { sebagian } \\
\text { indikator }\end{array}$ & $\begin{array}{l}\text { Tidak memenuhi } \\
\text { indikator }\end{array}$ \\
\hline & & & $\begin{array}{l}\text { Ketersediaan } \\
\text { Penunjuk Arah }\end{array}$ & $\begin{array}{l}\text { - Memberikan } \\
\text { penyediaan } \\
\text { penunukan } \\
\text { arah } \\
\text { - Letaknya } \\
\text { dipersimpang } \\
\text { an jalan. }\end{array}$ & $\begin{array}{l}\text { Hanya } \\
\text { memenuhi } \\
\text { sebagian } \\
\text { indikator }\end{array}$ & $\begin{array}{l}\text { Tidak memenuhi } \\
\text { indicator }\end{array}$ \\
\hline & & & $\begin{array}{l}\text { Kemudahaan } \\
\text { Mobilitas } \\
\text { Pergerakan }\end{array}$ & $\begin{array}{l}\text { - Jangkauan } \\
\text { dari } \\
\text { transportasi } \\
\text { umum <400m } \\
\text { dan lebih dari } \\
\text { l jenis moda } \\
\text { - Penyediaan } \\
\text { ruang parkir } \\
\text { (On street } \\
\text { parking dan } \\
\text { parking area }\end{array}$ & $\begin{array}{l}\text { Hanya } \\
\text { memenuhi } \\
\text { sebagian } \\
\text { indikator }\end{array}$ & $\begin{array}{l}\text { Tidak memenuhi } \\
\text { indicator }\end{array}$ \\
\hline
\end{tabular}


Dalam keberlanjutan penelitian ini di perlukannya data-data terkait dengan Aspek Revitalisasi Kawasan Wisata Cagar Budaya Laweyan yang berjenis data primer dan data sekunder. Data primer didapatkan melalui wawancara, penyebaran quesioner dan observasi lapangan. Wawancara ini dilakukan terhadap pihak-pihak terkait seperti Kelurahan serta pengelola kawasan (FPKBL), sedangkan quesioner diberikan kepada pengunjung untuk menilai persepsi kepuasaan.

Tabel 3. Sampel

\begin{tabular}{|c|c|c|c|c|}
\hline Sasaran & Populasi & Rumus & $\begin{array}{c}\text { Error } \\
\text { Level }\end{array}$ & Sampel \\
\hline Pengunjung & - & Daniel & $10 \%$ & 84 \\
\hline
\end{tabular}

Sumber: Daniel, et.al, 1986; Analisis Peneliti 2017

Sedangkan data sekunder adalah datadata institusional terkait dengan kawasan penelitian tersebut.

\section{HASIL DAN PEMBAHASAN}

Berdasarkan data-data yang diperoleh dan diolah, maka dapat disimpulkan beberapa hasil seperti berikut.

\subsection{Kesesuaian Variabel Daya Tarik Wisata}

Kesesuaian Daya Tarik Wisata ini dinilai dari 2 sub variabel yaitu Terjaganya Kelestarian Bangunan Cagar Budaya sebagai Daya Tarik serta Budaya dan Adat Tradisi sebagai Daya Tarik. Ketercapaian kesesuaian akan di tampilkan berdasarkan hasil temuan dan indikator penilaian kesesuaian yang telah ditetapkan, berikut adalah skoring kesesuaian terhadap Daya Tarik Wisata:

Tabel 4. Skoring Kesesuaian Kesesuaian Variabel Daya Tarik Wisata

\begin{tabular}{|c|c|c|c|c|c|}
\hline \multirow{6}{*}{  } & Sub Variabel & Parameter & Hasil & Skor & Ket. \\
\hline & \multirow{3}{*}{$\begin{array}{l}\text { Terjaganya } \\
\text { Kelestarian } \\
\text { Bangunan } \\
\text { Cagar Budaya } \\
\text { sebagai Daya } \\
\text { Tarik }\end{array}$} & $\begin{array}{l}\text { Terlindungannya } \\
\text { Bangunan Cagar } \\
\text { Budaya }\end{array}$ & $\begin{array}{l}\text { Presentase ketercapaian } \\
\text { perlindungan terhadap } \\
\text { bangunan cagar budaya } \\
\text { yang ada sebesar } 100 \% .\end{array}$ & $1 / 2$ & Sesuai \\
\hline & & $\begin{array}{l}\text { Perawatan } \\
\text { Bangunan Cagar } \\
\text { Budaya }\end{array}$ & $\begin{array}{l}\text { Presentase ketercapaian } \\
\text { perawatan terhadap } \\
\text { bangunan cagar budaya } \\
\text { yang ada sebesar } 0.092 \% \text {. }\end{array}$ & $1 / 6$ & $\begin{array}{c}\text { Tidak } \\
\text { Sesuai }\end{array}$ \\
\hline & & $\begin{array}{l}\text { Bangunan Cagar } \\
\text { Budaya sebagai } \\
\text { atraksi wisata }\end{array}$ & $\begin{array}{l}\text { Presentase ketercapaian } \\
\text { pemanfaatan bangunan } \\
\text { cagar budaya sebagai } \\
\text { daya tarik wisata sebesar } \\
0.26 \% \text {. }\end{array}$ & $1 / 6$ & $\begin{array}{l}\text { Tidak } \\
\text { Sesuai }\end{array}$ \\
\hline & \multirow{2}{*}{$\begin{array}{l}\text { Budaya dan } \\
\text { Adat Tradisi } \\
\text { sebagai Daya } \\
\text { Tarik }\end{array}$} & $\begin{array}{l}\text { Pelestarian } \\
\text { Budaya dan } \\
\text { Tradisi }\end{array}$ & $\begin{array}{l}\text { Presentase ketercapaian } \\
\text { pelestarian budaya dan } \\
\text { tradisi sebesar } 50 \% \text {. }\end{array}$ & $1 / 2$ & $\begin{array}{c}\text { Kurang } \\
\text { Sesuai }\end{array}$ \\
\hline & & $\begin{array}{l}\text { Budaya dan } \\
\text { tradisi sebagai } \\
\text { atraksi wisata }\end{array}$ & $\begin{array}{l}\text { Presentase ketercapaian } \\
\text { pemanfaatan budaya dan } \\
\text { tradisi sebagai daya tarik } \\
\text { wisata sebesar } 100 \% \text {. }\end{array}$ & $3 / 4$ & Sesuai \\
\hline & & & Jumlah & $21 / 12$ & $\begin{array}{c}\text { Kurang } \\
\text { Sesuai }\end{array}$ \\
\hline
\end{tabular}




\subsection{Kesesuaian Variabel Pelaku Kegiatan Wisata}

Kesesuaian Pelaku Kegiatan Wisata ini dinilai dari 3 sub variabel yaitu Kelembagaan, Kepuasan Pengunjung dan Produktifitas Ekonomi Lokal.
Ketercapaian kesesuaian akan di tampilkan berdasarkan hasil temuan dan indikator penilaian kesesuaian yang telah ditetapkan, berikut adalah skoring kesesuaian terhadap Pelaku Kegiatan Wisata:

Tabel 5. Skoring Kesesuaian Variabel Pelaku Kegiatan Wisata

\begin{tabular}{|c|c|c|c|c|c|}
\hline \multirow{6}{*}{ 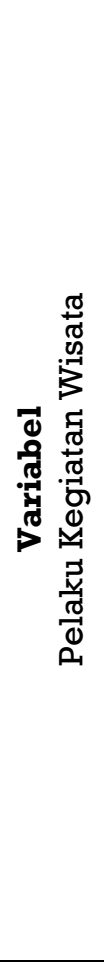 } & Sub Variabel & Parameter & Hasil & Skor & Ket. \\
\hline & \multirow{3}{*}{ Kelembagaan } & $\begin{array}{l}\text { Perencana/ } \\
\text { penggerak } \\
\text { kawasan wisata }\end{array}$ & $\begin{array}{l}\text { - Memiliki Visi dan Misi } \\
\text { - Memiliki tujuan dan } \\
\text { saran }\end{array}$ & $2 / 9$ & $\begin{array}{l}\text { Kurang } \\
\text { Sesuai }\end{array}$ \\
\hline & & $\begin{array}{l}\text { Media promosi } \\
\text { kawasan wisata }\end{array}$ & $\begin{array}{l}\text { - Promosi melalui leaflet } \\
\text { - Promosi melalui web } \\
\text { - Promosi melalui papan } \\
\text { informasi } \\
\text { - Promosi melalui TIC }\end{array}$ & $3 / 9$ & Sesuai \\
\hline & & $\begin{array}{l}\text { Monitoring } \\
\text { kawasan wisata }\end{array}$ & $\begin{array}{l}\text { - Sebagai mediator } \\
\text { kepada pemerintah dan } \\
\text { evaluasi (evaluator) } \\
\text { - Memberikan } \\
\text { pengetahuan dan } \\
\text { pengarahan kepada } \\
\text { masyarakat } \\
\text { (Pengawasan) }\end{array}$ & $2 / 9$ & $\begin{array}{l}\text { Kurang } \\
\text { Sesuai }\end{array}$ \\
\hline & $\begin{array}{l}\text { Kepuasaan } \\
\text { Pengunjung }\end{array}$ & $\begin{array}{l}\text { Kepuasaan } \\
\text { Pengunjung }\end{array}$ & $\begin{array}{l}\text { Nilai kepuasaan } \\
\text { pengunjung yakni } 1856 .\end{array}$ & 1 & Sesuai \\
\hline & $\begin{array}{l}\text { Produktivitas } \\
\text { Ekonomi } \\
\text { Lokal }\end{array}$ & $\begin{array}{l}\text { Daya saing } \\
\text { tenaga kerja } \\
\text { sektor } \\
\text { pariwisata }\end{array}$ & $\begin{array}{l}\text { Memiliki nilai } \\
\mathrm{LQ}=1.49\end{array}$ & 1 & Sesuai \\
\hline & & & Jumlah & $27 / 9$ & Sesuai \\
\hline
\end{tabular}

\subsection{Kesesuaian Variabel Fasilitas Fisik Wisata}

Kesesuaian pelestarian cagar budaya laweyan ini dinilai dari 6 parameter yaitu ketersediaan toko cinderamata, ketersediaan ruang terbuka hijau, ketersediaan jalur pejalan kaki, ketersediaan akomodasi wisata, ketersediaan penunjuk arah dan kemudahaan mobilitas pergerakan. Ketercapaian kesesuaian akan di tampilkan berdasarkan hasil temuan dan indikator penilaian kesesuaian yang telah ditetapkan, berikut adalah skoring kesesuaian terhadap ketersediaan infrastruktur fisik kawasan wisata: 
Tabel 6. Skoring Kesesuaian Ketersediaan Infrastruktur Fisik Kawasan Wisata

\begin{tabular}{|c|c|c|c|c|c|}
\hline \multirow{6}{*}{ 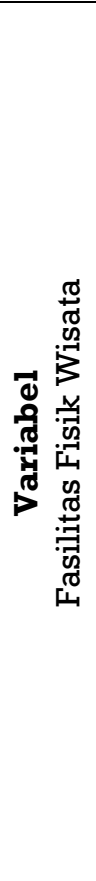 } & Sub Variabel & Parameter & Hasil & Skor & Ket. \\
\hline & \multirow{5}{*}{$\begin{array}{l}\text { Ketersediaan } \\
\text { Infrastruktur } \\
\text { Fisik Wisata }\end{array}$} & $\begin{array}{l}\text { Ketersedian Toko } \\
\text { Cinderamata }\end{array}$ & $\begin{array}{l}\text { - Memenuhi penyediaan } \\
\text { Toko Cinderamata } \\
\text { - Masyarakat menjadi } \\
\text { pelaku usaha.. }\end{array}$ & $1 / 2$ & Sesuai \\
\hline & & $\begin{array}{l}\text { Ketersediaan } \\
\text { Ruang Terbuka } \\
\text { Hijau }\end{array}$ & $\begin{array}{l}\text { Hanya terdapat ruang } \\
\text { terbuka hijau pasif } \\
\text { berupa jalur hijau dan } \\
\text { makam }\end{array}$ & $1 / 3$ & $\begin{array}{l}\text { Kurang } \\
\text { Sesuai }\end{array}$ \\
\hline & & $\begin{array}{l}\text { Ketersediaan Jalur } \\
\text { Pejalan Kaki }\end{array}$ & $\begin{array}{l}\text { - Belum adanya jalur } \\
\text { pejalan kaki }\end{array}$ & $1 / 6$ & Tidak Sesuai \\
\hline & & $\begin{array}{l}\text { Ketersediaan } \\
\text { Akomodasi Wisata }\end{array}$ & $\begin{array}{l}\text { - Jangkauan pelayanan } \\
\text { penginapan sudah } \\
\text { mencukupi kawasan } \\
\text { wisata } \\
\text { - Menyediakan paket } \\
\text { keliling kawasan wisata } \\
\text { dan paket membatik }\end{array}$ & $1 / 2$ & Sesuai \\
\hline & & $\begin{array}{l}\text { Ketersediaan } \\
\text { Penunjuk Arah }\end{array}$ & $\begin{array}{l}\text { - Persebaran penunjuk } \\
\text { arah sebesar } 80 \% \text { di } \\
\text { seluruh kawsan }\end{array}$ & $1 / 3$ & $\begin{array}{l}\text { Kurang } \\
\text { sesuai }\end{array}$ \\
\hline & & $\begin{array}{l}\text { Kemudahaan } \\
\text { Mobilitas } \\
\text { Pergerakan }\end{array}$ & $\begin{array}{l}\text { - Terjangkau oleh } \\
\text { transportasi umum } \\
\text { - Belum adanya kantong } \\
\text { parkir khusus }\end{array}$ & $1 / 3$ & $\begin{array}{l}\text { Kurang } \\
\text { sesuai }\end{array}$ \\
\hline & & & Jumlah & $21 / 6$ & $\begin{array}{l}\text { Kurang } \\
\text { Sesuai }\end{array}$ \\
\hline
\end{tabular}

Dari hasil pencapaian pada ke tiga aspek yang meliputi Daya Tarik Wisata, Pelaku Kegiatan Wisata dan Fasilitas Fisik Wisata, diketahui bahwa kesesuaian pencapaian Revitalisasi Kawasan Wisata Cagar Budaya Laweyan secara keseluruhan adalah sesuai. Walaupun hanya terdapat satu aspek yang sesuai yakni Pelaku Kegiatan Wisata dan kedua aspek lainya memiliki nilai yang kurang sesuai, namun hal tersebut tidak menjadikan niali keseluruhan aspek menjadi kurang sesuai. Selengkapnya dapat dilihat pada tabel berikut ini :

Tabel 7. Sintesis Skoring Kesesuaian

\begin{tabular}{|c|l|c|c|}
\hline No & \multicolumn{1}{|l|}{ Variabel } & $\begin{array}{c}\text { Hasil } \\
\text { Skor }\end{array}$ & Kategori \\
\hline 1 & Daya Tarik & 2 & Kurang \\
& Wisata & $1 / 12$ & Sesuai \\
\hline
\end{tabular}

\begin{tabular}{|c|c|c|c|}
\hline No & Variabel & $\begin{array}{c}\text { Hasil } \\
\text { Skor }\end{array}$ & Kategori \\
\hline 2 & $\begin{array}{l}\text { Pelaku } \\
\text { Kegiatan } \\
\text { Wisata }\end{array}$ & $27 / 9$ & Sesuai \\
\hline 3 & $\begin{array}{l}\text { Fasilitas Fisik } \\
\text { Wisata }\end{array}$ & $2^{1 / 6}$ & $\begin{array}{l}\text { Kurang } \\
\text { Sesuai }\end{array}$ \\
\hline & Jumlah & $7^{1 / 36}$ & Sesuai \\
\hline
\end{tabular}

Sumber: Analisis Peneliti, 2017

Walaupun nilai secara keseluruhan sudah memiliki nilai yang sesuai dilihat dari Aspek Revitalisasi Kawasan Wisata Cagar Budaya, namun terdapat beberapa hal yang dirasa masih kurang terutama pada aspek Fasilitas FIsik Wisata. Dalam penyediaannya masih dirasa banyak yang kurang seperti tidak adanya penyediaan lahan parkir. Tidak adanya lahan khusus parkir yang terdapat pada kawasan wisata ini menimbulkan banyak masalah terutama 
terkait masalah mobilitas yang ada di dalam kawasan itu sendiri, sehingga penambahan zona khusus parkir sangatlah diperlukan guna memberikan kenyamanan yang lebih kepada pengunjung yang datang.

Tidak adanya jalur pejalan kaki yang khusus untuk mengakomodir pejalan kaki juga dirasa masih kurang pada kawasan tersebut. Hal ini bisa ditingkatkan guna memberikan kenyamanan yang lebih kepada pengunjung shingga pengunjung yang datang dapat lebih menikmati kawasan dengan cara berjalan kaki.

\section{Kesimpulan}

Kesesuaian Komponen Kawasan Wisata Kampung Laweyan ini dapat dilihat dari 3 komponen yaitu Daya Tarik Wisata, Pelaku Kegiatan Wisata dan Fasilitas Fisik Wisata. Hasil dari analisis ketiga komponen tersebut secara keseluruhan mendukung atau telah sesuai jika ditinjau dari Aspek Revitalisasi Kawasan Wisata Cagar Budaya. Walaupun dari ketiga komponen yang ada hanya terdapat satu komponen yang telah sesuai yaitu komponen Pelaku Kegiatan Wisata sedangkan komponen yang lain memiliki nilai yang kurang sesuai, hal tersebut tidak merubah nilai keseluruhan komponen kawasan wisata ini yaitu pada nilai sesuai.

Belum optimalnya perawatan dan pemanfaatan bangunan cagar budaya sebagai daya tarik yang ada menyebabkan daya tarik dalam kawasan tersebut kurang. Hal tersebut dapat dioptimalkan lagi dengan lebih mampu mengeksplor bangunan cagar budaya yang ada tanpa mengesampingkan unsur sejarah dan budaya yang ada. Penyediaan fasilitas fisik yang belum optimal juga memberikan kesan yang kurang nyaman terhadap wisatawan yang ada, seperti contohnya penyediaan jalur pejalan kaki serta penyediaan lahan parkir yang masih sangat kurang. Perbaikan terhadap aspek-aspek fisik ini dirasa perlu guna lebih menunjang aktifitas di dalam kawasan wisata tersebut.

Berdasarkan temuan dan kesimpulan yang telah dijabarkan diatas, maka rekomendasi yang dapat disampaikan peneliti untuk pemerintah terkait kebijakan selanjutnya yang baiknya dibuat dan untuk penelitian selanjutnya yang menjadikan penelitian ini sebagai acuan dasar permasalahan yang bisa dikembangkan lagi sesuai perkembangan zaman adalah sebagai berikut:

a) Untuk Pemerintah Kota Surakarta

Kesesuaian yang ada pada Kampung Laweyan ini memiliki potensi yang lebih sebagai kawasan wisata cagar budaya, adanya campur tangan pemerintah sebagai stackeholder pengembangan kawasan dirasa akan dapat mengembangkan kawasan ini menjadi kawasan wisata unggulan di Kota Solo. Penambahan dan perbaikan kualitas fisik pada kawasan ini dirasa perlu guna lebih menghidupkan lagi kawasan tersebut, namun hal yang perlu diperhatikan yakni untuk tetap mempertahankan ciri dan karakteristik yang sudah ada.

b) Untuk Penelitian Selanjutnya

Pada penelitian ini dalam penghimpunan data terpatok kepada instansi terkait (FPKLB,Dinas dan Kelurahan) serta hanya 
mempertimbangkan responden dari pengunjung. Untuk penelitian selanjutnya diharapkan mampu untuk mengeksplore secara lebih luas seperti kepada masyarakat dan pemilik usaha yang ada di kawasan ini.

\section{REFERENSI}

Daniel, Wayne W. dan Terrel, James $C$. 1986. Business Statistic: Basic Concept and Methodology. $883 \mathrm{hlm}$. Edisi 4. Sevilla: Houghton Mifflin

Danisworo, M, Martokusumo, W. 2002. Revitalisasi Kawasan Kota: Sebuah Catatan Dalam Pengembangan dan Pemanfaatan Kawasan Kota. Info URDI Vol.13

Kecamatan Dalam Angka Laweyan Tahun 2016.

Majah, Ibnu. 2015. Laweyan dalam Periode Krisis Ekonomi hingga Menjadi Kawasan Wisata Sentra Industri Batik tahun 1998-2004. Semarang : UNNES

Mulyandari, Hestin. 2010. Pengantar Arsitektur Kota. Yogyakarta :Penerbit Andi.

Yoeti, Oka A. 1982. Pengantar Ilmu Pariwisata. Bandung: Angkasa

Inskeep, Edward. 1991. Tourism Planning: An Integrated and Suistainable Approach. Van Nostrand Reindhold. New Yorwk,Inc 